\title{
Prevalence of stillbirth and associated Factors among immediate post-partum mothers at Felegehiwot comprehensive specialized hospital, northwest Ethiopia: An institution based cross- sectional study
}

\section{Agerie Mengistie}

Teda Health Sciences College

Mulusew Andualem

Bahir Dar University, School of Public health

koku Tamirat ( $\square$ kokusisay23@gmail.com )

University of Gondar

Research article

Keywords: Stillbirth, predictors, immediate post-partum, Felegehiwot Referral Hospital

Posted Date: July 19th, 2019

DOI: https://doi.org/10.21203/rs.2.11593/v1

License: (c) (1) This work is licensed under a Creative Commons Attribution 4.0 International License.

Read Full License 


\section{Abstract}

Background Stillbirth rates are important indicators of the quality of antenatal and obstetric care in the community. In Ethiopia many neonatal deaths and almost all stillbirths are underreported. Therefore, this study aimed to determine prevalence of still birth and associated factors among immediate post-partum mothers. Methods An institution based cross-sectional study was employed at Felegehiwot comprehensive specialized hospital from March to May $2016(n=310)$. A pretested structured interviewer administered questionnaire and medical chart reviews were used to collect data from immediate postpartum mothers. Data were entered using Epi Info version 3.5.4 and analyzed using SPSS version 20. Bivariate and multivariable logistic regression model was fitted to identify predictors of stillbirth. Adjusted Odds Ratio (AOR) with a 95\% confidence interval (Cl) was computed to assess the strength of association. Variables with p-value less than 0.05 in the multivariable considered as significant predictors of stillbirth. Result The prevalence of stillbirth was $8.7 \%$ with $(95 \% \mathrm{Cl}: 5.8,12.4)$. Previous history of stillbirth; [AOR=4.7, 95\% Cl (1.90-24.76)], labor complications [AOR=4.9, 95\% Cl (1.30-18.58)], Parthogragh use $[A O R=0.25,95 \% \mathrm{Cl}(0.10-0.80)]$, and twin delivery [AOR=6.7, 95\% $\mathrm{Cl}(1.40-32.74)]$ were significant predictors of stillbirth. Conclusion The magnitude of stillbirth in this study was higher. Multiple pregnancies, previous stillbirth, and complicated labor positively associated with stillbirth. Whereas use of partograph during labor significantly reduced stillbirth. This finding suggests that proper management of labor is mandatory to reduce stillbirth.

\section{Background}

The World Health Organization (WHO) defined stillbirth as baby born with no signs of life at or after the age of viability (28 weeks' gestation)[1]. Globally, approximately 4 million stillbirths occurs every year, of whom, half million stillbirths occur at the time of labor and the majority of cases occurred in developing countries[2]. In Sub-Saharan Africa, stillbirths account for more than $3 \%$ of all deliveries each year[3]. The average stillbirth rate in developing countries has been reported to be 26 per 1000 births, which is five times higher than developed countries of 5 per 1000 births[2, 4]. Stillbirths occurred during perinatal period of which half of all stillbirths occurred in the intra partum period of labor and delivery[5]. Stillbirths were constituted the highest rates of all the adverse pregnancy outcomes and common in developing countries[6].

Stillbirth rates are important indicators of the quality of antenatal and obstetric care in the community[7]. Reports of stillbirths and mortality came from officially registered deaths, however most of cases are under reported. The underreporting of neonatal death and stillbirth is neglected and hidden in the global health agenda usually resulted from low institutional delivery. Isolation of women and newborn during postpartum period, community norm of acceptance of newborn death as normal, home delivery and low utilization of vital registration in the country were factors contributed for lower report of stillbirth [7]. Magnitudes of stillbirths vary in different low- and middle-income countries ranged from 35.6 to 6.8 per 1000 births in Bangladesh and Thailand, respectively [8, 9]. Quality of antenatal and obstetric care and most of which are thought to be preventable. Different factors associated with stillbirth and other adverse 
birth outcome, such as socio-demographic characteristics of a women (age, marital status, occupation and place of residence), obstetrical characteristics (parity, previous still birth, obstetrical infections, fetal presentation, obstetric complications and Rh iso-immunization) and health service factors (ANC and intra partum management) [3, 8, 10-16]. Different interventions made to lessen the impact of stillbirths such as focused antenatal care for pregnant women and increasing institutional delivery were some of the interventions. There is limited study conducted in the study area regarding the magnitude and determinants of stillbirth.

Hence, this study aimed to assess the prevalence of stillbirth and associated factors among immediate post-partum mothers. The finding of this study might be used to reduce adverse birth outcomes based on evidences.

\section{Methods And Materials}

\section{Study design setting and period}

An institution based cross-sectional study design was employed at Felegehiwot comprehensive specialized hospital from March 10 to May 10, 2016. The city is located $565 \mathrm{Km}$ from Addis Ababa in the northwest Ethiopia. According to Amhara Bureau of finance and economic development report, the city hosts a population of 277,566 . In the town there are six governmental health centers, one comprehensive specialized hospital and five higher private clinics.

Regarding, to maternal health services of Felegehiwot comprehensive specialized hospital has obstetrics, high risk, and Gynecology wards used for patient admission and evaluation. The hospital serves more than five million people in the catchment area and neighboring regions.

\section{Population of the study}

All mothers who gave birth at Felegehiwot comprehensive specialized hospital were the source population for this study. All mothers who give birth to fetus of whose gestational age was 28 completed weeks and above were eligible and took part in the study.

\section{Sample Size and Sampling Procedure}

Sample size was determined using single population proportion with the assumptions of proportion of stillbirth was 7.1\% [10], 3\% margin of error, and 95\% confidence interval $(\mathrm{Cl})$ and taking 10\% no-response rate. The final calculated sample sized became 310 . The systematic random sampling technique was used to select the final study participants. According to Feleghwiote comprehensive specialized hospital statistics on average $6000,500,17$ deliveries reported annually, monthly, and daily correspondingly. 


\section{Data collection procedure}

Pre-tested structured interviewer-administered questionnaire and medical chart review were used to collect data about socio-demographic and clinical characteristics. Initially, the questionnaire was prepared in English then translated to local language (Amharic) and back to English by language expert to check its consistency. After extensive evaluation, final version of the questionnaire was developed. The questionnaire contained information on socio-demographic profile, obstetric, gynecological, and behavioral, health status, medications taken and birth outcome. Moreover, to supplement the primary data, with chart reviews of target mothers were used. Two diploma and one BSc midwives were recruited from Bahir Dar Health Science College as data collectors and supervisor, respectively. Mothers immediately after delivery, before leaving the maternity ward were interviewed.

To maintain data quality, one day training was given for supervisors and data collators on questionnaire contents, data quality and confidentiality respondents before data collection. On daily basis principal investigator and supervisor checked completeness and consistency of collected questionnaires.

\section{Data processing and analysis}

Data were coded and entered in to Epi Info version 7 and exported to SPSS version 20 for further processing and analysis. Descriptive statistics such as mean, median, proportions were carried out and text, graph, and tables were used to present the data. Binary logistic regression model was fitted to identify factors associate with still birth. Crude and Adjusted Odds ratio with $95 \% \mathrm{Cl}$ were used to describe the strength of association between outcome and predictor variables. Variables with $\mathrm{p}$ value less than 0.05 in the multivariable model considered as statistical significantly associated with stillbirth.

\section{Results}

\section{Socio-demographic characteristics}

A total of 310 respondents were recruited with response rate of $100 \%$. The mean (SD) age of mothers was $26.6( \pm 5)$ years, most $(94.5 \%)$ of them were married, $(60.6 \%)$ were urban dwellers, and more than two third $(68.1 \%)$ of them were housewives. More than one-third (38.4\%) of respondents were unable to read and write, majority ( $87.1 \%$ ) of mothers were orthodox Christians (Table 1 ).

\section{Obstetrics related characteristics}

More than half (56.5\%) of mothers were multiparous, most ( $84.6 \%)$ of them had interparty interval $\geq 2$ years from current parity. The majority $(91.0 \%)$ of mothers had at least one ANC follow up for the current delivery and most of the recent pregnancies (89\%) were wanted, planned and supported. Nearly two-third $225(72.5 \%)$ of the mothers were delivered at term and proportion of preterm delivery was $16.2 \%$. Majority 
(89.0\%) of labor initiated spontaneously and $47.4 \%$ of mothers had at least one obstetric complications, of which, ante partum hemorrhage, pregnancy induced hypertension, and anemia were the most common complications. More than one fifth (12.1\%) of participants had premature rapture of membrane (PROM) in the current labor delivery process (Table 2).

\section{Labor and delivery related characteristics}

More than half (53.5\%) mothers gave birth through spontaneous vaginal delivery, most $(93.9 \%)$ of deliveries were single, $63.2 \%$ newborns were male, and to $67.7 \%$ labors Partograph were used. The mean birth weight was $1810 \mathrm{SD} \pm 491$ grams, nearly one-fourth $23.5 \%$ had was low birth weight. Historically, $11.0 \%$ of women had experience of stillbirth in the preceding births. Two third (Table 3 ).

\section{Prevalence of stillbirth among immediate postpartum mothers}

This study showed the magnitude of stillbirth were $8.7 \%$ with (95\% Cl: $5.8 \% 12.4 \%$ ) among total births. Of stillbirths, $59.3 \%$ were occurred after admitted to the hospital with positive fetal heart beat.

\section{Factors associated with stillbirth}

In the multivariable logistic regression analysis; twin delivery, Paratograph use, previous history of still birth, and labor complication were significant predictors of stillbirth at a p-value 0.05 . Mothers who had history of labor complication the odds of still birth was 4.9 [AOR $=4.995 \% \mathrm{Cl}(1.30-18.58)]$ times higher compared to those mothers who had no complications. Similarly, mother who gave twin delivery the odds of stillbirth were 6.7 [AOR $=6.7,95 \% \mathrm{Cl}(1.40-32.74)]$ times higher compared to those who gave singleton birth. Those mothers whose labor were followed by using Partograph the odds of stillbirth were decreased by $75 \%$ [AOR $=0.25,95 \% \mathrm{Cl}(0.10-0.80)]$ compared to those mothers whose who had not used. The odds of stillbirth were $4.7[\mathrm{AOR}=4.7 ; 95 \% \mathrm{Cl}(1.90-24.76)]$ times higher among those mothers who had history of stillbirth in the previous pregnancies compared to those who had no such history. (Table 4)

\section{Discussion}

The prevalence of still birth in this study was $8.7 \%$ with (95\%Cl: $5.8 \% 12.4 \%)$. This finding was consistent with the results from Hospitals in Ethiopia ranged from $6 \%$ to $7.72 \%[6,10,11,16,17]$. However, this finding was higher than results from Tanzania (3.6\%)[18], Zambia (3.4\%)[19], Ghana (2.39\%)[3], Malawi (3.6\%)[20], Nigeria (2.34)[12], and Gamo Gofa, Southern Ethiopia (1.9\%)[14]. This finding was also higher than study findings from EDHS 2011(1.8\%), EDHS 2016 (11.7 per 1000 births)[21]. Similarly, the current finding is higher than a systemic review from sub-Saharan African countries where the prevalence of still birth ranged from 2.1 to $3.3 \%$ [22]. The possible explanations for the observed variations might be because of quality of health service, socio-cultural factors and community awareness. In addition, methodological differences between studies where community based studies underestimated the 
prevalence and under reporting of stillbirth among community members are common. Furthermore, most of the deliveries in the referral hospitals were complicated and transferred from other primary health facilities which increased the probability of stillbirth. Despite better health services and high skilled professionals in the hospitals, delays from mother's health seeking behaviors and poor referral system in the lower health facilities contributed to increased rate of stillbirth in the health facilities.

Previous stillbirth history were associated with increased stillbirth outcome the current delivery. This finding was consistent with the study result in Nigeria[12]. This might be due to the fact women who had experience of stillbirth in the preceding births were at higher risk of having recurrent stillbirths[23]. Since poor obstetrics histories are recurrent and with unknown underlying causes. Similarly complication during labor and delivery associated with increased stillbirth occurrence compared those who had normal labor and delivery. This finding was also comparable with study done in Mekelle town, Tigray regional State, Ethiopia [13]. Complications during labor and delivery might induced intra-uterine oxygen inadequacy which leads to fetal distress which leads to stillbirth. This finding was line with other finding in India[24]. Findings of this study specified that, multiple pregnancy was associated with increased occurrence of stillbirth compared singleton birth. The reason could be intrauterine growth restrictions and birth defects and mechanical factors that are common in multiple pregnancy which increased the vulnerability of stillbirth and these multiple pregnancies require special medical interventions which is more accessible and available in our study area. This result is in agreement with findings in northwest Ethiopia [11].

Labor and delivery which was followed by using partograph associated with lower occurrence of stillbirth compared those who do not used. Since partograph is a labor follow up chart recommended by WHO, appropriate use of partograph can help health professionals to early detection of danger signs during labor[25]. Therefore, it can prevent stillbirth by early detection and prompt management of labors at highest risk of complications and danger signs. It also tells us the quality of intra partum care[8, 16]. From 27 stillbirths found in this study majority 16 (59.7\%) of stillbirths were occurred during intra partum period that can be averted with the appropriate intra partum care during labor complications like preterm labor, prolonged second stage of labor and mechanical factors (like obstructed labor, uterine rupture, malpresentations, mal-position). In addition, non-reassuring fetal heart rate had significantly association with stillbirth outcomes. This is supported by systematic review study done from sixteen hospitals and community based prenatal mortality studied in Ethiopia [22]and agree with other reports[20, 26]. Therefore, identification and management of the complications and provision of care by skilled health care providers, availability and utilization of comprehensive emergency obstetric care may improve and keys to reducing stillbirths. Consequently, there is a need to reinforce and improve health workers' abilities to properly monitor women in labor at all levels of care for early identification and management of complications. This includes early referral if a woman is at a health center has complications during antenatal follow up and labor delivery process.

\section{Limitation}


Firstly, since it was based on institutional study it is difficult to generalize to the whole community.

Secondly, this study shared the limitations of cross-sectional studies and hence may not be possible to establish temporal cause effect relationship between adverse birth outcomes and explanatory variables. Besides, as the study was in a referral hospital, it may overestimated the stillbirth rate and not show the real picture of these stillbirth outcomes in the area

\section{Conclusions}

The magnitude of stillbirth in this study was higher. Multiple pregnancies, previous stillbirths, complicated labor associated with increased stillbirth. Whereas, the use of partograph significantly reduced stillbirth. This finding suggests that proper management of labor is mandatory to reduce stillbirth.

\section{Abbreviations}

ANC: Antenatal Care, AOR: Adjusted Odds Ratio, Cl: Confidence Interval, EDHS, Ethiopia demography and Health Suurvey, IUFD: Intera-Uterine Fetal Death, PROM: Premature Rupture of Membrane, SD Standard Deviation, SPSS: Statistical package for Social Science, WHO: world Health Organization

\section{Declarations}

\section{Ethics approval and consent to participate}

Ethical approval was obtained from the ethical committee of College of Medicine and Health Sciences, Bahir Dar University. Letter of permission was also obtained from Amhara Regional State Health Bureau and Felegehiwot Comprehensive Referral Hospital. Verbal informed consent was obtained from each study participant. Similarly; the participants were informed about purpose of the study. Participants were also informed on data confidentiality issues, on voluntary basis and they can refuse from the study at any time if they are not comfortable on the questionnaire at any step.

\section{Consent for publication}

Not applicable

\section{Availability of data and material}

Data will be shared up on reasonable request from the corresponding author.

\section{Authors' contributions}


AM conceived the study. AM, MA and KST equally participated in the design, data collection, statistical analysis and writing-up of the manuscript. All authors read and approved the final manuscript.

Competing interest

The authors declared that they have no competing interest.

\section{Acknowledgments}

We would like to thank Bahir Dar University, college of Medicine and Health Science School of nursing for the opportunity given to us to conduct this title. We would like to thank school of nursing for their support by writing letter of cooperation for Felege Hiwot Referral Hospital to get the data. We would like thank study participants, data collectors and supervisors for their collaboration.

\section{Funding}

No funding was obtained

\section{References}

1. Fretts, R. and C. Spong, Fetal Death and Stillbirth: Incidence, Etiology, and Prevention. Fetal Death and Stillbirth: Incidence, Etiology, and Prevention. Uptodate, nd Web, 2017. 28.

2. Blencowe, H., et al., National, regional, and worldwide estimates of stillbirth rates in 2015, with trends from 2000: a systematic analysis. The Lancet Global Health, 2016. 4(2): p. e98-e108.

3. BG., K., Risk factors associated with stillbirth. a case study of the hohoe municipality, ghana. Kwame Nkrumah University of Science and Technology., 2011: p. 1-102.

4. Barros, F.C., et al., Global report on preterm birth and stillbirth (3 of 7): evidence for effectiveness of interventions. BMC pregnancy and childbirth, 2010. 10(1): p. S3.

5. Ahmed, I., et al., Population-based rates, timing, and causes of maternal deaths, stillbirths, and neonatal deaths in south Asia and sub-Saharan Africa: a multi-country prospective cohort study. The Lancet Global Health, 2018. 6(12): p. e1297-e1308.

6. World Health Organzition . Addis Ababa, E.I.I.C., Maryland, USA. , Ethiopia Demographic and Health Survey. WHO .Ethiopia and Calverton, Maryland, USA:, 2011. 69: p. 153-158.

7. Molla M. , Yirgu R., and G.A. . A Qualitative Study of Attitudes and Values Surrounding Stillbirth and Neonatal Mortality Among Grandmothers, Mothers, and Unmarried Girls in Rural Amhara and Oromiya Regions, Ethiopia. Journal of Midwifery \&Women's Health(www.Jmwh.org., 2014. 59: p. 1-8.

8. Eshete AS., Birhanu D., and W. B., Birth outcomes among Laboring Mothers in Selected Health Facilities of North Wollo Zone, Northeast Ethiopia.. Bahir Dar, Ethiopia, 2013. 5:7, (http://dx.doi.org/10.4236/health.2013.57154). 
9. Aminu, M., et al., Causes of and factors associated with stillbirth in low-and middle-income countries: a systematic literature review. BJOG: An International Journal of Obstetrics \& Gynaecology, 2014. 121: p. 141-153.

10. Adane A., et al., Adverse birth outcomes among deliveries at Gondar University Hospital, Northwest Ethiopia. Open Access, 2014. 14: p. 2-8.

11. Andargie G., et al., Predictors of perinatal mortality in rural population of Northwest Ethiopia: a prospective longitudinal study. BMC Public 2013. 13: p. 1471-2458.

12. Audu BM., et al., Risk Factors for Stillbirths at Universty of Maiduguri Teaching Hospital, Maiduguri, Nigeria: A Cross-Sectional Retrospective Analysis. Niger Med J 2009. 50: 2.

13. Berhe H., Berhe H., and Z. D., Factors Associated with Patterns of Birth outcome at Public Hospitals In Mekelle Town, Tigray Region, Ethiopia: A Case-Control Study. Innovative Association, 2013. 2: p. 6781.

14. Gebremeskel, F., et al., Determinants of Adverse Birth Outcome among Mothers who Gave Birth at Hospitals in Gamo Gofa Zone, Southern Ethiopia: A Facility Based Case Control Study. Quality in Primary Care, 2017. 25(5): p. 259-266.

15. Tachiweyika E., et al., Determinants of perinatal mortality in Marondera district, Mashonaland East Province of Zimbabwe .a case control study. Pan African Medical, 2011. 8:7.

16. y., G., Assessment of Factors Associated with Perinatal Mortality among Public Hospital Deliveries in Addis Ababa, Ethiopia. Addis Ababa University, 2015: p. 1-51.

17. Berhan Y. and B. AS., Perinatal Mortality Trends in Ethiopia. Ethiop J HealthSciences, 2014. http://dx.doi.org/10.4314/ejhs.v24i1.4S.

18. LöfwanderM., Stillbirths and Associations with maternal education from a regional hospital in north Eastern Tanzania. University of Troms $\varnothing$, Norway, 2012.

19. Turnbull E., et al., Causes of Stillbirth, Neonatal Death And Early Childhood Death In Rural Zambia by Verbal Autopsy Assessments. Tropical Medicine and International Health., 2011. 16 (894-901).

20. Lily C, JohanneS., and O. J., Factors Associated with Perinatal Deaths in Women Delivering in a Health Facility in Malawi. Journal of Research in Nursing and Midwifery (JRNM). 2012. 1:5: p. 69-79.

21. CSA, I., Ethiopia demographic and health survey 2016. Addis Ababa, Ethiopia and Calverton, Maryland, USA: Central Statistical Agency and ICF International, 2012. 430.

22. Say L., et al., The prevalence of stillbirths: a systematic review. Open Access, 2006. 3: p. 1-11.

23. Lamont, K., et al., Risk of recurrent stillbirth: systematic review and meta-analysis. bmj, 2015. 350: p. h3080.

24. Behal M. and V. R., Maternal Risk Factors For Perinatal Mortality in india. Indian Journal of Obstetrics and Gynecology Research., 2015. 2(6): p. 92-9.

25. Meena, R., et al., Outcome of labour monitored by WHO modified partograph and latent phase partograph. infection, 2016. 2(3): p. 4. 
26. Bayou G. and B. Y., Perinatal Mortality and Associated Risk Factors. Ethiop J Health Sci, 2012. 22: 3: p. 153-154.

\section{Tables}

Table 1:-Socio-demographic characteristic of mothers who gave birth at Bahir Dar Felegehiwot Referral Hospital, 2016(n=310)

\begin{tabular}{|l|l|l|}
\hline Characteristics & Frequency & Percentages \\
\hline Age & & \\
\hline$<\mathbf{2 0}$ & 15 & 4.8 \\
\hline $\mathbf{2 0 - 3 4}$ & 261 & 84.8 \\
\hline $\mathbf{> 3 5 +}$ & 34 & 11 \\
\hline Marital status & & \\
\hline Married & 274 & 88.4 \\
\hline Single & 36 & 11.6 \\
\hline Residence & & \\
\hline Rural & 122 & 39.4 \\
\hline Urban & 188 & 60.6 \\
\hline Educational status & & \\
\hline Unable read and write & 119 & 38.4 \\
\hline Primary and secondary school & 105 & 33.9 \\
\hline College and above & 86 & 27.7 \\
\hline Income level in ETB & & \\
\hline$<1500$ & 167 & 53.9 \\
\hline 1500-2500 & 80 & 25.8 \\
\hline$>$ 2500 & 63 & 20.3 \\
\hline Religion & & \\
\hline Orthodox & 270 & 87.1 \\
\hline Muslim & 37 & 11.9 \\
\hline Others & 3 & 0.9 \\
\hline Occupation & & \\
\hline Housewife & 214 & 68.9 \\
\hline Employed & 90 & 29.1 \\
\hline Other & & 2.2 \\
\hline & & \\
\hline
\end{tabular}


Table 2: Obstetrics and related characteristics of mothers who gave birth at Felegehiwot comprehensive specialized hospital, 2016(n=310)

\begin{tabular}{|c|c|c|}
\hline Characteristics & Frequency & Percentages \\
\hline \multicolumn{3}{|l|}{ Condition of current Pregnancy } \\
\hline Planned, wanted and supported & 264 & 85.2 \\
\hline Unplanned & 46 & 14.8 \\
\hline \multicolumn{3}{|c|}{ Current pregnancy birth interval $(n=175)$} \\
\hline$<2$ years & 27 & 15.4 \\
\hline$\geq 2$ years & 148 & 84.6 \\
\hline \multicolumn{3}{|l|}{ Parity } \\
\hline 1 & 140 & 45.2 \\
\hline $2-4$ & 138 & 44.5 \\
\hline$>5+$ & 32 & 10.3 \\
\hline \multicolumn{3}{|l|}{ Previous history of stillbirth } \\
\hline Yes & 34 & 11.0 \\
\hline No & 276 & 89.0 \\
\hline \multicolumn{3}{|l|}{ Gestational age in weeks } \\
\hline Term & 225 & 72.5 \\
\hline Preterm term & 49 & 16.2 \\
\hline Post term & 36 & 11.6 \\
\hline \multicolumn{3}{|l|}{ ANC follow up } \\
\hline Yes & 282 & 91.0 \\
\hline No & 28 & 9.0 \\
\hline \multicolumn{3}{|l|}{ Obstetric complications } \\
\hline No & 163 & 52.6 \\
\hline Yes & 147 & 47.4 \\
\hline \multicolumn{3}{|c|}{ Obstetric and medical complications $(n=147)$} \\
\hline Pregnant induced Hypertension & 39 & 26.2 \\
\hline Oligo-hydraminouse & 11 & 7.4 \\
\hline Gestational diabetes mellitus & 5 & 3.4 \\
\hline Ante partum hemorrhage & 23 & 15.4 \\
\hline RH-factor & 19 & 12.8 \\
\hline Anemia & 8 & 5.4 \\
\hline Preterm & 49 & 16.2 \\
\hline PROM & 18 & 12.1 \\
\hline Previous caesarean section & 9 & 6.0 \\
\hline Others* & 6 & 4.0 \\
\hline
\end{tabular}


Note: others* chorioaminitis, IUGR (intra uterine growth restriction)

Table3:- Labor and delivery related characteristics of mothers and birth outcome at Felegehiwot Comprehensive Specialized Hospital, 2016

\begin{tabular}{|l|l|l|}
\hline Characteristics & Frequency & Percentage \\
\hline Labor complications & \multicolumn{2}{|l|}{} \\
\hline Yes & 163 & 52.6 \\
\hline No & 147 & 47.4 \\
\hline Labor complications(n=163) & \multicolumn{2}{|l|}{} \\
\hline Non reassuring fetal heart rate pattern & 50 & 15.5 \\
\hline Prolonged labor & 48 & 16.1 \\
\hline Mal presentation & 25 & 8.1 \\
\hline Obstructed labor & 11 & 3.5 \\
\hline Malposition & 8 & 2.6 \\
\hline Uterus rupture & 10 & 3.2 \\
\hline Others* & 11 & 3.6 \\
\hline Status of labor & & \\
\hline Spontaneous & 276 & 89.0 \\
\hline Induced /augmented & 34 & 11.0 \\
\hline Sex of newborn & & \\
\hline Male & 196 & 63.9 \\
\hline Female & 114 & 42.1 \\
\hline Mode of delivery & & \\
\hline Caesarean section & 119 & 38.4 \\
\hline Instrumental & 25 & 8.1 \\
\hline Spontaneous vaginal delivery & 166 & 53.5 \\
\hline Weight of new born baby & 73 & \\
\hline <2500g & 13 & 22.5 \\
\hline 25000-4000g & & \\
\hline$\geq 4000 g$ & & \\
\hline & & \\
\hline
\end{tabular}

Note: others*. Cord prolapsed, chorioaminitis. 
Table 4: Bi-variable and multivariabel logistic regressions on different variables towards stillbirth in post-partum mother who gave birth at FelegeHiwot Referral Hospital, 2016 $(\mathrm{n}=310)$

\begin{tabular}{|c|c|c|c|c|}
\hline \multirow[t]{2}{*}{ Variables } & \multicolumn{2}{|c|}{$\begin{array}{c}\text { Still } \\
\text { birth }\end{array}$} & \multirow{2}{*}{$\begin{array}{l}\text { Crud OR } \\
(95 \% \text { CI) }\end{array}$} & \multirow[t]{2}{*}{$\begin{array}{l}\text { Adjusted } \\
\text { OR(95\%CI) }\end{array}$} \\
\hline & Yes & No & & \\
\hline \multicolumn{5}{|l|}{ Residence } \\
\hline Urban & 10 & 178 & 1 & 1 \\
\hline Rural & 17 & 105 & $\begin{array}{l}2.88(1.49- \\
7.94)\end{array}$ & $1.12(0.35 \quad 3.62)$ \\
\hline \multicolumn{5}{|c|}{ History of still birth } \\
\hline No & 20 & 256 & 1 & 1 \\
\hline Yes & 7 & 27 & $\begin{array}{l}3.31(1.24- \\
8.20)\end{array}$ & $4.7(1.90 \quad 24.76)$ \\
\hline \multicolumn{5}{|l|}{ Parity } \\
\hline 1 & 9 & 131 & 1 & 1 \\
\hline $2-4$ & 13 & 125 & $\begin{array}{l}1.5(0.63 \\
3.67)\end{array}$ & $1.6(0.47 \quad 5.72)$ \\
\hline 5 & 5 & 27 & $\begin{array}{l}2.7(0.84 \\
8.68)\end{array}$ & $3.3(0.09 \quad 3.91)$ \\
\hline \multicolumn{5}{|c|}{$\begin{array}{l}\text { History of labor } \\
\text { complication }\end{array}$} \\
\hline No & 4 & 140 & 1 & 1 \\
\hline Yes & 23 & 143 & $\begin{array}{l}5.6(2.05 \\
17.20)\end{array}$ & $4.9(1.30 \quad 18.58) \square$ \\
\hline \multicolumn{5}{|c|}{ Parthogragh used } \\
\hline No & 15 & 86 & 1 & 1 \\
\hline Yes & 12 & 197 & $\begin{array}{l}0.35(0.16 \\
0.78)\end{array}$ & $0.25\left(\begin{array}{ll}0.10 & 0.80\end{array}\right)$ \\
\hline \multicolumn{5}{|c|}{ Type of delivery } \\
\hline Single & 21 & 270 & 1 & 1 \\
\hline Twin & 6 & 13 & $\begin{array}{l}5.9(2.05 \\
17.20)\end{array}$ & $6.7(1.39 \quad 32.74) \square$ \\
\hline \multicolumn{5}{|c|}{ Sex of new born } \\
\hline Female & 6 & 108 & 1 & 1 \\
\hline Male & 21 & 175 & $\begin{array}{l}2.2(1.85 \\
5.52)\end{array}$ & $4.3(0.2314 .91)$ \\
\hline
\end{tabular}

* show a p-value $\leq 0.05$ 